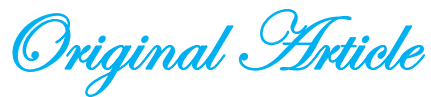

\title{
HER2 Over Expression in Malignant Palpable Breast Lumps of Pre and Postmenopausal Women Attending RICK. Abdelbadie A ${ }^{1}$, Mustafa RA ${ }^{2}$, Omer $\mathrm{H}^{3}$, Abdalla $\mathrm{SM}^{4}$, Mohamed $\mathrm{SY}^{5}$.
}

\begin{abstract}
:
Back ground: Human Epidermal growth factor Receptor 2 (HER-2/neu) over expression in breast cancer is associated with poor outcome and decrease disease free survival (DFS). The aim of this study was to evaluate the over expression of HER2/neu among premenopausal and postmenopausal females presented with malignant palpable breast lumps to Radio Isotope Center Khartoum (RICK). Methods: The study was a case-control conducted among patients attending Radiation Isotopes Centre Khartoum (RICK). A total of 328 women were randomly selected. Data were collected by a pre coded, pre tested questionnaire. Tissue biopsies of breast lumps had been analyzed using immunohistochemical techniques for HERR-2/neu over expression and its relation to other prognostic factors was evaluated.
\end{abstract}

Results: HER-2/neu + vein first pregnancy at $\geq 23$ years, were $32(41 \%)$ in the cases, $6(35 \%)$ in the controls of premenopausal women, and 21(44\%) in the cases, $5(38 \%)$ in the controls of postmenopausal women. HER-2/neu + veexpression in relation to age at menarche $\leq 12$ years was $39(51 \%)$ in the cases, $7(39 \%)$ in the controls of premenopausal women, and $36(56 \%)$ in the cases, $7(45 \%)$ in the controls of postmenopausal women. HER-2/neu+ vein relation to Body Mass Index $>29 \mathrm{~kg} / \mathrm{m}^{2}$ showed $7(37 \%)$ in the cases, $2(33 \%)$ in the controls of premenopausal women $(\mathrm{x} 2=0.024)$, and $8(38 \%)$ in the cases, $2(40 \%)$ in the controls of postmenopausal women $(\mathrm{x} 2=$ 0.006). HER-2/neu+ veexpression in relation to history of abortion or miscarriage (ever) was found to be $21(39 \%)$ in the cases, $4(33 \%)$ in the controls of premenopausal women, and $18(44 \%)$ in the cases, $3(33 \%)$ in the controls among postmenopausal women. HER-2/neu+ veexpression in relation to the history of breast cancer in a first degree relatives was $3(25 \%)$ in the cases, $1(50 \%)$ in the controls of premenopausal women, and $4(22 \%)$ in the cases, $2(28 \%)$ in the controls of postmenopausal women. HER-2/neu+ veexpression in relation to the use of oral contraceptives was $3(37 \%)$ in the cases, $1(50 \%)$ in the controls among premenopausal women, and $3(27 \%)$ in the cases, $1(50 \%)$ in the controls of postmenopausal women.

Conclusion: The study confirmed an etiological association between HER2/neu+ve and HER2/neu - ve and age at first pregnancy $\geq 23$ years, age of menarche at $\leq 12$ years, abortion or miscarriage in premenopausal and postmenopausal Sudanese women, while an etiological association was confirmed between HER2/neu+ve and HER2/neu -ve, and BMI in premenopausal women, and the family history of cancer in pos menopausal women.

Keywords: Human Epidermal, Growth factor, Receptor.

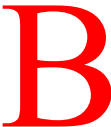

reast cancer is the commonest cancer in women; it is rising at a rate of approximately $2 \%$ per year in all

\section{population ${ }^{1}$.}

1. Department of Pathology, Faculty of Medicine, National Ribat University, Sudan.

2. Department of Histopathology, RICK, Sudan.

3. Faculty of Medicine, University of Gezira, Sudan

4. Faculty of Medicine, National Ribat University.

5. Faculty of Medicine, University of Khartoum.

Correspondence: elsadigoo@gmail.com
The number of annual deaths from breast cancer has remained about the same for the last 50 years, although the number of cases is increasing. This shows the benefits of early detection, which impacts survival ${ }^{2}$. In Sudan, breast cancer accounts for $34.5 \%$ of all female cancers. There is an alarming high frequency of women presenting with advanced breast cancer to the Radiation Isotope Center Khartoum (RICK). 
Human Epidermal growth factor Receptor2 (HER2/neu), a protein receptor found on the surface of cells, is a key component in regulating cell growth. When the HERa gene (sometimes written HER2/neu) is altered, extra HER2 receptors may be produced. The HER2/neu oncogene, also known as c-erb-B2, c-neu or ERBB2, is located in chromosome 17q11.2-12, encoding an EGFR- family like glycoprotein $^{3}$. Its amplification, which is strongly correlated with protein over expression, occurs in about $15-43 \%$ of breast tumors. This over expression of HER2 causes increased cell growth and reproduction often resulting in more aggressive tumor cells. HER 2 protein over expression affects $25 \%$ to $30 \%$ of breast cancer patients ${ }^{4}$. Indeed, several studies have demonstrated that HER$2 /$ neu amplification represents a prognostic and predictive marker; its expression is associated with early disease recurrence, relative resistance to chemo- and / or hormone therapy and short survival ${ }^{5}$. In most studies, over expression of HER2 was associated with adverse prognosis independent of other prognostic factors, even when multivariate analysis was used for the outcome analysis ${ }^{6}$.

The aim of this study was to evaluate the HER2/neu expression in malignant breast palpable lumps among pre-menopausal and post-menopausal females who attended RICK.

\section{Methods:}

Study design: This was a case-control study to evaluate the tumor marker (ER-PR- and HER-2/neu) over expression in malignant breast lumps of Sudanese females.

Setting: The study was conducted in RICK, from January 2006 to August 2008. RICK, which is located in Khartoum, is the first Radio Isotope Center in the Sudan and receives patients from all over the country.

Study population: Sudanese females attended RICK during the study period were enrolled in the study. Subjects were classified as pre and postmenopausal. If the menstrual cycles had ended naturally at least 12 months before the interview, surgery or radiation therapy at any age the subject was considered to be postmenopausal. Those who reported not having menstrual cycles for the last 10 months were considered as premenopausal and were combined with premenopausal women.

Sampling: 328 females were selected using convenience sampling. An age-stratified random sample of 100 women was used as a control group from screened patients who were free of $\mathrm{Ca}$. breast.

Data collection: Personal interviews were conducted with each woman during her first visit to the center (both patients and controls) using a structured, pre coded, pre tested questionnaire. Anthropometric measurements (weight and height) were also taken. Biopsies were taken from the breast lumps of the selected patients. The biopsies were far from the tumor margins. The specimens were directly placed in neutral buffer formation and considered for histopathology and immunohistochemistry.

Data analysis: Data were analyzed by Odds ratio and Chi-square, using SPSS version 13.

Ethical considerations: The aim of the study was fully explained to the patients and controls. A verbal consent to participate was obtained from the participant, and their right to withdraw from the study was explained to the patients. Respect and privacy of the participants were maintained throughout the study period. Ethical clearance was obtained from the Ethical Committee, Federal Ministry of Health.

\section{Results:}

HER-2/neu + vein first pregnancy at $\geq 23$ years, were $32(41 \%)$ in the cases, $6(35 \%)$ in the controls of premenopausal women (Odds ratio $(\mathrm{OR})=1.3$, Chi-square $\left.\left(\mathrm{X}^{2}\right)=0.234\right)$, and $21(44 \%)$ in the cases, $5(38 \%)$ in the controls of postmenopausal women (Odds ratio $=1.24$, Chi-square $=0.138$ ).

HER-2/neu + veexpression in relation to age at menarche of 12 years was $39(51 \%)$ in the cases, $7(39 \%)$ in the controls of premenopausal women ((The ORs was 1.61, Chi-square $=1.25)$, and $36(56 \%)$ in the cases, 
$7(45 \%)$ in the controls of postmenopausal women (The ORs was 1.1, Chi-square $=0.25$ ). HER-2/neu+ vein relation to Body Mass Index $>29 \mathrm{~kg} / \mathrm{m}^{2}$ showed $7(37 \%)$ in the cases, $2(33 \%)$ in the controls of premenopausal women $(\mathrm{x} 2=0.024)$, and $8(38 \%)$ in the cases, $2(40 \%)$ in the controls of postmenopausal women $(\mathrm{x} 2=0.006)$.

HER-2/neu+ veexpression in relation to history of abortion or miscarriage (ever) was found to be $21(39 \%)$ in the cases, $4(33 \%)$ in the controls of premenopausal women, and 18 $(44 \%)$ in the cases, $3(33 \%)$ in the controls among postmenopausal women.
HER-2/neu+ veexpression in relation to the history of breast cancer in a first degree relatives was $3(25 \%)$ in the cases, $1(50 \%)$ in the controls of premenopausal women, and 4 $(22 \%)$ in the cases, $2(28 \%)$ in the controls of postmenopausal women.

HER-2/neu+ veexpression in relation to the use of oral contraceptives was $3(37 \%)$ in the cases, $1(50 \%)$ in the controls among premenopausal women, and $3(27 \%)$ in the cases, $1(50 \%)$ in the controls of postmenopausal women (Table1).

Table (1): Relation between HER-2/neu over expression and risk factors among pre and postmenopausal patients with malignant breast lumps attending RICK and their controls

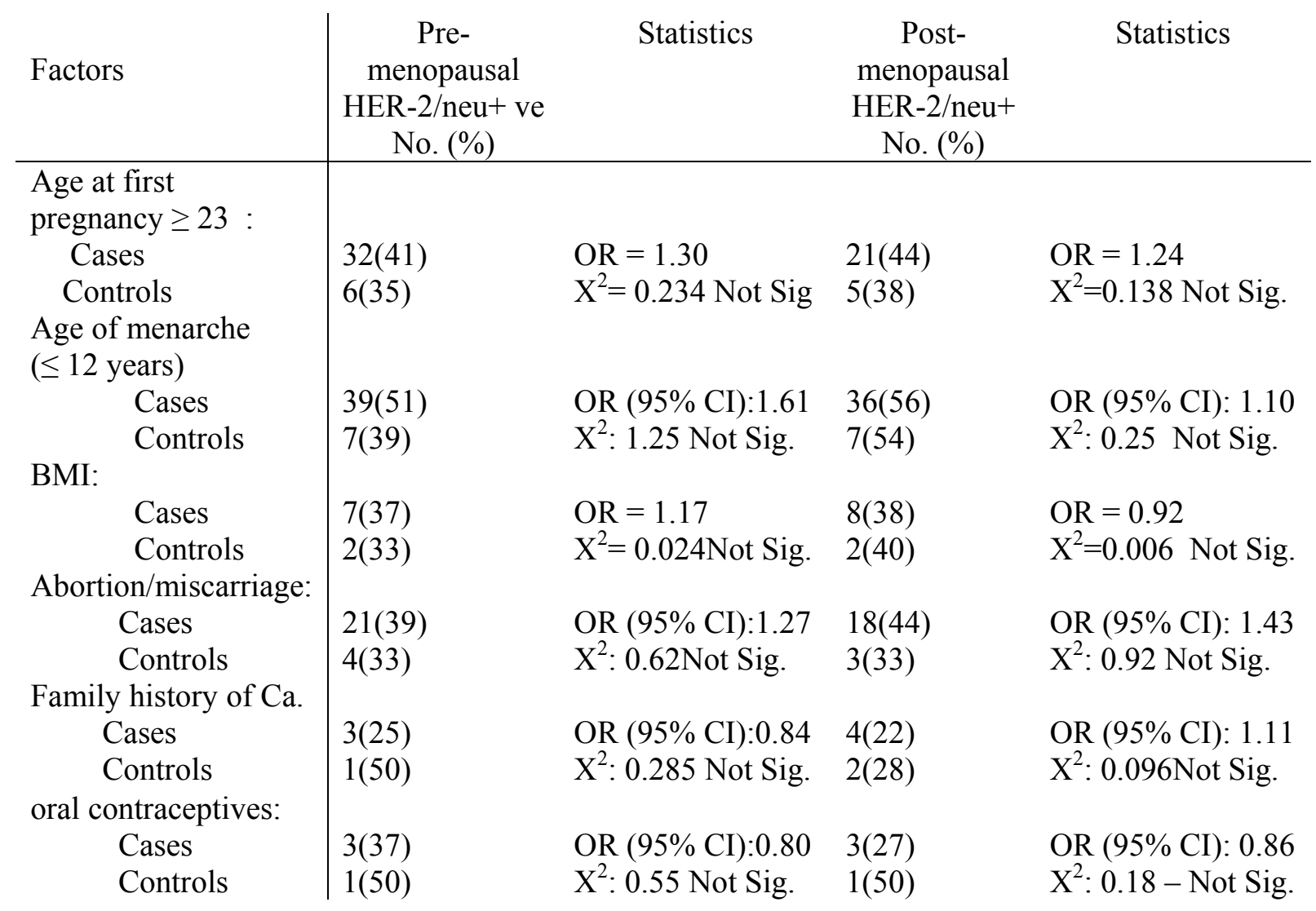

\section{Discussion:}

In contrast with other investigators ${ }^{7}$ who have shown an elevated risk for HER-2/neu+ve tumors with an early age at first full pregnancy, we found an elevated risk with a late age regardless of HER-2/neu protein expression, but the comparison between
HER-2/neu+ve and HER-2/neu-ve tumors revealed an association with HER-2/neu+ve breast cancers. The relation between HER$2 /$ neu + ve in the first pregnancy at $\geq 23$ years in the cases and controls was not significant in pre and postmenopausal women. 
Obesity was related to breast cancer in post menopausal females whom cancer cells over express HER-2/neu oncoprotein. In fact increase BMI elevated the risk in both groups but the comparison between HER-2/neu+ veand HER-2/neu- tumors revealed a much stronger association with HER-2/neu+ vebreast cancers. The comparison between Estrogen Receptors ER+ and ER - tumors revealed a much stronger association with ER + breast cancers.

Few studies have examined the possibility whether HER-2/neu status can help to discriminate etiologically between distinct subgroups of breast cancer cases, and none of them has identified the effect of increased BMI to HER-2/neu positive tumors ${ }^{8-11}$.

Previous findings ${ }^{10,11}$ suggested an inverse relationship between abortion and HER$2 /$ neu + vebreast cancers, while we also found this inverse association but independently of HER-2/neu status. Interestingly, abortion increased the risk for HER-2/neu+ vetumors only in the premenopausal women.

More specifically, compared to investigators ${ }^{7}$ who have shown an elevated risk for HER$2 /$ neu+ vetumors with an early age at menarche, we found also, an elevated risk with an early age regardless of HER-2/neu protein expression. The comparison between HER-2/neu+ veand HER-2/neu- tumors revealed a much stronger association with HER-2/neu+ vebreast cancers. These findings were in agreement with previous reports ${ }^{11}$.

We found that previous family history of cancer was related to postmenopausal breast tumors that over express HER-2/neu+ve. While previous family history of cancer was related with premenopausal breast tumors that were HER-2/neu-ve. These findings were in agreement with Vlachonikolis IG et $\mathrm{al}^{11}$.

Early use of contraceptives has been positively associated with HER-2/neu+ vebreast cancer $^{7,} 12$, but our findings were different, revealing a positive association with HER-2/neu-ve tumors. However, because the number of oral contraceptive and hormone replacement therapy (HRT) users in this study was small, this subgroup analysis was hindered by decreased power to detect associations of any magnitude.

Our findings have similarities and differences with respect to previous reports that examined the associations of breast risk factors with HER-2/neu status. This inconsistency may reflect differences in study design, individuals, and laboratory methodology. In this study we used immunochemistry (CB11 monoclonal antibody) to assess the HER$2 /$ neu protein over expression, which is highly correlated with gene amplification according to previous reports. Also, the percentage of women with breast cancer and HER-2/neu protein over expression found here was within the limits reported elsewhere.

\section{Conclusion:}

The study confirmed an etiological association between HER2/neu+ and HER2/neu - and age at first pregnancy $\geq 23$ years, age of menarche at $\leq 12$ years, abortion or miscarriage in both premenopausal and postmenopausal Sudanese women, while an etiological association was confirmed between HER2/neu+ and HER2/neu -, and BMI in premenopausal women, and the family history of cancer in postmenopausal women. The study did not reveal an etiological association between HER-2/ neu and use of oral contraceptive in pre and postmenopausal women. As a result of this study, statistical significance was not confirmed between HER2/neu+ and HER2/neu -, and age at first pregnancy $\geq 23$ years, age of menarche at $\leq 12$ years, abortion or miscarriage, BMI, family history of cancer and use of oral contraceptive in pre and postmenopausal women. HER2/neu immunohistochemistry can be used as a reliable indicator of the presence of mutated nuclear HER2/neu protein. Whether this method can be performed reliably in clinical practice may need further studies. The value of HER2/neu as a prognostic indicator, and its correlation with other prognostic factors needs further investigation as well. 
Abdelbadie A et al.

\section{References:}

1. Parkin DM, Muirc CS, Whelar SL et al. Cancer incidence in five continents 120- International Agency for Research on Cancer (IARC). Lyon. 1992.

2. Underwood JCE. General and systematic pathology, $2^{\text {nd }}$ ed. Churchill Livingstone; 1996. PP . 82.

3. Hall JM, Lee MK, Newman B, et al.: Linkage of early-onset familial breast cancer to chromosome 17q21. Science 250(4988): 1684-1689, 1990.

4. Taucher S, Rudas M, Mader RM et al.: Do we need HER-2/neu testing for all patients with primary breast carcinoma .Cancer 2003, 98:2547-2553.

5. Revillion F, Bonneterre J, Peyrat JP: ERBB2 oncogene in human breast cancer and its clinical significance. Eur J Cancer 1998, 34:791-808.

6. Ross JS, Fletcher JA, Linette GP et al. The Her2/neu gene and protein in breast cancer 2003: biomarker and target of therapy. Oncologist 2003, 8:307-325.

7. Olsson H, Borg A, Ferno $M$ et al. Her-2/neu and INT2 proto- oncogene amplification in malignant breast tumours in relation to reproductive factors and
HER2 over expression in women attending RICK.

exposure to exogenous hormones. J NatI Cancer Inst, 1999, 83: 1483- 1487.

8. Treurniet HF, Rookus MA, Petrese HL et al. Differences in breast cancer risk factors to neu ( cerbB2) protein overexpression of the breast tumor. Cancer Res 1992, 52: 2344 - 2345.

9. Liberman L, Dershaw DD, Rosen PP et al. Stereotaxic core biopsy of impalpable spiculated breast masses. AJR Am. J Roentgenol 1995;165:551-554.

10. Huang WY, Newman B, Millikan RC et al. Risk of breast cancer according to the status of HER2/ neu oncogene amplification. Cancer Epidemiol Biomarkers Prev 2000, 9: 65-71.

11. Vlachonikolis IG, Aletra TJ, Georgoulias V: Incidence of breast cancer on Crete, 1994 - 1995. Eur J Cancer 2002, 38: 574 - 577.

12. Gammon MD, Hibshoosh H, Terry MB, Bose S et al. Oral contraceptive use and other risk factors in relation to HER-2/neu overexpression in breast cancer among young women. Cancer Epidemiol Biomarkers Prev 1999, 8: $413-419$. 